\title{
BMJ Open Risk factors for suicidal thoughts in adolescence-a prospective cohort study: the Young-HUNT study
}

\author{
Arve Strandheim, ${ }^{1,2}$ Ottar Bjerkeset,, ${ }^{3,4}$ David Gunnell, ${ }^{5}$ Sigrid Bjørnelv, ${ }^{3,6}$ \\ Turid Lingaas Holmen, ${ }^{2}$ Niels Bentzen ${ }^{2}$
}

To cite: Strandheim A, Bjerkeset 0 , Gunnell D, et al. Risk factors for suicidal thoughts in adolescence-a prospective cohort study: the Young-HUNT study. BMJ Open 2014;4:e005867. doi:10.1136/bmjopen-2014005867

- Prepublication history for this paper is available online. To view these files please visit the journal online (http://dx.doi.org/10.1136/ bmjopen-2014-005867).

Received 6 June 2014 Revised 24 July 2014 Accepted 1 August 2014
CrossMark

For numbered affiliations see end of article.

Correspondence to Dr Arve Strandheim; arve. strandheim@ntnu.no

\section{ABSTRACT}

Objectives: Examining the associations between health and lifestyle factors recorded in the participants' early teens and development of suicidal thoughts recorded 4 years later.

Design: Population-based prospective cohort study. Settings: All students in the two relevant year classes in Nord-Trøndelag County were invited, $80 \%$ attended both waves of data collection.

Participants: 2399 secondary school students who participated in the Young-HUNT1 study in 1995-1997 (13-15 years old) were included in a follow-up study 4 years later (17-19 years old).

Primary outcome measure: Suicidal thoughts reported at age $17-19$ years.

Results: 408 (17\%, $95 \% \mathrm{Cl} 15.5 \%$ to $18.5 \%)$ of the adolescents reported suicidal thoughts at follow-up, $158(14.2 \%, \mathrm{Cl} 13.6 \%$ to $16.4 \%)$ boys and 250 (19.5\%, Cl $18.8 \%$ to $22.0 \%)$ girls. Baseline anxiety and depressive symptoms (adjusted OR (aOR) 1.9, Cl 1.4 to 2.6 ), conduct problems ( $\mathrm{aOR} 1.8, \mathrm{Cl} 1.3$ to 2.6 ), overweight (aOR $1.9 \mathrm{Cl} 1.4$ to 2.4), and muscular pain and tension (aOR 1.8, $\mathrm{Cl} 1.4$ to 2.4), were all associated with reporting suicidal thoughts at follow-up.

Conclusions: One in six young adults experienced suicidal thoughts, girls predominating. Suicidal thoughts were most strongly associated with symptoms of anxiety/depression, conduct problems, pain/tension and overweight reported when participants were 13-15 years old. Specific preventive efforts in these groups might be indicated. Future research should investigate whether similar associations are seen with suicide/suicidal attempts as endpoints.

\section{INTRODUCTION}

Suicidal thoughts and suicidal behaviours develop during adolescence and peak late in adolescence and early adulthood. ${ }^{1}$ Recent findings from population-based studies indicate that suicidal thoughts and attempts are parts of a continuum and share a common risk profile. ${ }^{23}$ It is well known from general population studies that anxiety and depression

\section{Strengths and limitations of this study}

- Whole county cohort study with follow-up after 4 years.

- Exposure variables: behaviour/health traits, outcome: suicidal thoughts.

- Suicidal thoughts were prevalent in late adolescence, boys $14.2 \%$ and girls $19.5 \%$.

- Suicidal thoughts were associated with anxiety/ depression, conduct problems, pain/tension and overweight in early adolescence.

contribute to raised suicide risk, ${ }^{4-6}$ yet some prospective studies have also linked anxiety and depression to increased incidence of suicidal thoughts. ${ }^{3}{ }^{7-9}$ In adolescence, externalising disorders such as ADHD and conduct disorders have been associated with suicidal attempts and to a lesser extent suicidal thoughts. ${ }^{10} 11$ Further, there is empirical support that childhood adversities, such as low social support, sexual abuse, domestic violence and maternal depression, influence the development of suicidal thoughts during adolescence. ${ }^{4} 712$ The findings from studies on weight problems, underweight and overweight and suicidal thoughts are contradictory, but overweight is often reported as a risk factor among adults. ${ }^{13-15}$ Even though adult alcohol problems contribute to a 10 -fold increase in suicide-related mortality, ${ }^{16}$ the relationship between alcohol use and suicidal thoughts in adolescence is sparsely studied in the last decade. ${ }^{17} 18$ Further, sleep disturbance, ${ }^{19}$ pain, especially headache, ${ }^{20}$ 21 smoking and reduced physical activity ${ }^{22-24}$ have all been reported to have a positive association with suicidal ideation in the adolescent general population.

Complex and partly paradoxical findings on gender differences complicate the understanding of adolescent suicidal ideation and behaviour. While girls report suicidal thoughts more often than boys during 
adolescence, ${ }^{25}{ }^{26}$ completed suicide in adolescence and young adulthood is 3-4 times more common in males than females in the Western World. ${ }^{25} 2728$ The prevalence of suicidal thoughts among girls peaks at about 16 years of age, while it continues to increase beyond the age of 19 in boys. ${ }^{29}$ Intriguingly, in adults overweight may be predictive of suicide among men and a risk factor among women in the general population. ${ }^{14} 30$

However, few large scale prospective studies have examined a wide range of risk factors and protective factors for suicidal thoughts among adolescent boys and girls.

The aim of this exploratory population study was to investigate the association of different risk factors in early adolescence with the development of suicidal thoughts 4 years later. Based on the existing literature we hypothesised that girls, individuals with high levels of anxiety and depression, inattentiveness, conduct problems, and alcohol-intoxications at baseline would be at increased risk of suicidal thoughts at follow-up.

\section{METHOD}

\section{Study design, setting and participants}

Young-HUNT1, the first wave of the adolescent part of the HUNT Study (Nord-Trøndelag Health Study) (http://www.ntnu.no/hunt/english), ${ }^{31}$ took place between 1995 and 1997. All teenagers (13-19 years) attending secondary and high schools in the county were invited to participate and $90 \%$ attended. In Young-HUNT2, (2000-2001) students in the last 2 years of high school or vocational training (age 17-19) were invited; of these $2399(80 \%)$ attended Young-HUNT1 and 2. The mean follow-up time was 3.9 years.

At baseline and follow-up, the participants completed a self-report questionnaire in class and underwent a physical examination, including height and weight.

All 2399 students who took part in Young-HUNT1 and 2 were included in the present study, but analyses of associations with weight are based on the 2271 participants who took part in the clinical examination.

\section{Ethics}

All the potential participants and their parents received a written statement about the study one month prior to the collection of the data, making discussion possible before signing the consent. Voluntary participation was stressed to the adolescents and their parents.

\section{Measures}

The Young-HUNT questionnaire includes a broad spectrum of health-related variables relevant for this study (http://www.ntnu.edu/hunt/data/que). Some categorical variables were already dichotomised, other variables (such as anxiety and depressive symptoms, attention and conduct problems, pain and tension symptoms) were based on instruments with multiple subquestions and alternative answers; categorisation of responses to these questions was based on factor analysis, described in earlier studies. ${ }^{32} 33$

\section{Outcome measure at follow-up}

\section{Suicidal thoughts}

At follow-up the students were asked: 'Have you had thoughts about taking your own life?' (yes/no). Positive responses were labelled as suicidal thoughts.

\section{Exposure variables at baseline}

Anxiety and depressive symptoms

Derived from the symptom checklist $90 \mathrm{R},{ }^{34}$ an abbreviated and previously validated five-item scale, SCL- $5,{ }^{35} 36$ was integrated in the questionnaire.

According to the previous studies ${ }^{37}$ and to our factor analysis, we included all five items in our variable.

\section{Attention and conduct problems}

A 14-item school-adjustment questionnaire was included in Young-HUNT, described in previous studies, ${ }^{32} 38$ which was utilised to define attention and conduct variables. A factor analysis identified two separate factors: attention problems and conduct problems. Conduct problems include disagreement with teachers, such as quarrels and scolding, as well as involvement in fights at school; attention problems include inattention and hyperkinetic symptoms. The summarised scores of all items in each category were dichotomised into low or high scores, defining scores above the 70th centile for the study population as high.

\section{Pain and tension symptoms}

The following four items constituted the pain/tension variable: headache, neck pain, muscle and joint pain, and palpitations during the past 12 months. The values were dichotomised according to the 70th centile, defining students with score above that as high. ${ }^{33}$

\section{Alcohol use}

Baseline alcohol status was defined using number of reported alcohol intoxications. Students answered the question: 'Have you ever been drunk?'. The variables were dichotomised to 'never' or 'ever', and named 'early alcohol intoxication'. For further differentiation early alcohol intoxications were divided into three: none, 1-3, 4 and more (table 3).

\section{Smoking}

Smoking at baseline was assessed using the question: 'Do you smoke?' (yes/no). Current smoking was defined as 'yes' to smoking daily or occasionally.

\section{Sleep disturbance}

Baseline sleep disturbance was defined as difficulties initiating sleep; 'In the last month, have you had difficulty falling asleep?'. 'Almost every night' and 'often' were classified as insomnia in accordance with former research. $^{39}$ 


\section{Physical activity}

Level of physical activity at baseline was estimated using the question: 'With exception of school activity, how many days a week do you practice sports or exercise to the point where you breathe heavily and/or sweat?'. 'Four days a week or more' was classified as being regularly physically active. ${ }^{40}$

\section{Height and weight}

Height and weight were measured by especially trained nurses to the nearest centimetre and nearest $0.5 \mathrm{~kg}$, respectively, with light clothes, without shoes, jacket or outdoor garments. Body mass index (BMI ${ }^{41}$ was calculated as body weight $(\mathrm{kg})$ divided by the square value of height $(\mathrm{m})$. Using the age-specific and gender-specific BMI cut-offs for children and adolescents recommended by the International Obesity Task Force underweight was defined corresponding to BMI $18.5 \mathrm{~kg} / \mathrm{m}^{2}$ or less in adults. ${ }^{42}$ Overweight was defined using age-specific and gender-specific BMI-cut-offs corresponding to BMI interval between 25 and 30 in adults and obese was defined with cut-offs corresponding to BMI 30 and beyond in adults.

\section{Statistics}

PASW Statistics 18 was used for data analysis. Frequencies are given as percentages and 95\% CIs for proportions were included for comparison. Logistic regression was the main statistical analysis in the study, presenting results as ORs with $95 \%$ CI.

In the main analysis, univariable logistic regression analyses were first used to examine the crude associations between health and behavioural exposures with suicidal ideation at follow-up. Results were stratified on gender with adjustment only carried out for age. Then all the variables were entered in the same models stratified by gender (table 2), thus adjusting for each other in addition to age. The fully adjusted models in this study include only participants that completed all the variables used from the questionnaire and had participated in the clinical examination, giving a total number of completers as 1911 in these models.

According to the results from former studies using the Young-HUNT data set, ${ }^{33} 43$ several clinically relevant statistical interactions were tested for. In the present study, interactions were shown between gender and overweight ( $p=0.01$ ), possible interactions also between gender and anxiety/depressive symptoms $(\mathrm{p}=0.09)$, pain and tension $(\mathrm{p}=0.10)$ and early alcohol intoxication $(\mathrm{p}=0.09)$. Accordingly, all analyses were stratified by gender (table 2). Further, there were possible interactions shown between early alcohol intoxication and anxiety/depressive symptoms $(p=0.07)$ or physical activity $(p=0.05)$, analysing for suicidal thoughts. To control for these potential interactions, analysis stratified on the presence of early alcohol intoxication were conducted, but only gave modest effect on the ORs and are not shown here.

\section{RESULTS}

Altogether 2399 students (80\% of the eligible) completed the questionnaire in both waves of the study, 1115 boys $(46.5 \%)$ and 1284 girls. 2271 students answered the question on suicidal thoughts at follow-up; 408 students $(17 \%)$ reported having had suicidal thoughts and the prevalence was $14.2 \%$ (CI $13.6 \%$ to $16.4 \%$ ) in boys and $19.5 \%$ (CI $18.8 \%$ to $22.0 \%$ ) in girls.

At baseline, symptoms of anxiety and depression were more frequent among girls (21\%, CI $18.8 \%$ to $23.2 \%)$, than boys $(11.5 \%$, CI $9.6 \%$ to $13.4 \%$ ) (table 1 ), as was daily or occasionally smoking: girls $(12.1 \%$, CI $10.3 \%$ to $13.9 \%$ ), boys $(7.8 \%$, CI $6.2 \%$ to $9.4 \%)$. Conduct problems were more frequent among boys $(16.2 \%$, CI $14.4 \%$ to $18.4 \%)$, than girls $(5.3 \%$, CI $4.1 \%$ to $6.5 \%)$

\begin{tabular}{|c|c|c|c|c|c|c|}
\hline & \multicolumn{2}{|c|}{ Total } & \multicolumn{2}{|c|}{ Boys } & \multicolumn{2}{|c|}{ Girls } \\
\hline & $\overline{\mathbf{N}}$ & Per cent & $\overline{\mathbf{N}}$ & Per cent & $\mathbf{N}$ & Per cent \\
\hline \multicolumn{7}{|l|}{ Mental health variables } \\
\hline Anxiety/depressive symptoms & 397 & 16.5 & 128 & 11.5 & 269 & 21.0 \\
\hline Attention problems & 448 & 18.7 & 188 & 16.9 & 260 & 20.2 \\
\hline Conduct problems & 249 & 10.4 & 181 & 16.2 & 68 & 5.3 \\
\hline Insomnia (DIS) & 185 & 7.7 & 67 & 6.0 & 118 & 9.2 \\
\hline \multicolumn{7}{|l|}{ Physical health variables } \\
\hline Pain and tension problems & 453 & 18.9 & 148 & 13.3 & 305 & 23.8 \\
\hline Underweight ${ }^{\star}$ (total $\mathrm{N}=2210$ ) & 149 & 6.2 & 60 & 5.4 & 89 & 6.9 \\
\hline Overweight $^{*}$ (total $\mathrm{N}=2210$ ) & 303 & 12.6 & 138 & 12.4 & 165 & 12.9 \\
\hline Obesity (total $\mathrm{N}=2210$ ) & 64 & 2.7 & 35 & 3.1 & 29 & 2.3 \\
\hline \multicolumn{7}{|l|}{ Lifestyle factors } \\
\hline Early alcohol intoxication(s) & 624 & 26.0 & 267 & 23.9 & 357 & 27.8 \\
\hline Physical activity (4 days/week or more) & 697 & 29.1 & 397 & 35.6 & 300 & 23.4 \\
\hline Daily or occasional smoking & 248 & 10.3 & 87 & 7.8 & 161 & 12.1 \\
\hline
\end{tabular}


and more boys were physically active $(35.6 \%$, CI $32.8 \%$ to $38.4 \%)$, compared to girls $(23.4 \%$, CI $21.1 \%$ to $25.7 \%)$.

In the univariable age-adjusted models (table 2), anxiety and depressive symptoms, attention and conduct problems, insomnia, pain/tension problems and smoking at baseline more than doubled the odds for suicidal thoughts at follow-up in both genders. Alcohol intoxication and overweight at baseline had moderate effects on suicidal thoughts $(50-70 \%$ increase) in both genders (table 2), whereas underweight did not show an influence on suicidal ideation in this study. Physical activity 4-7 days a week had a protective effect (OR 0.7, CI 0.5 to 0.9 ), whereas smoking at baseline increased odds for suicidal thoughts 4 years later (OR 2.1, CI 1.5 to 2.8 ).

In the fully adjusted model stratified by gender, anxiety and depressive symptoms (aOR 1.9, CI 1.4 to 2.6), together with pain and tension problems (aOR 1.8, CI 1.4 to 2.4) still seemed strongly associated with later suicidal ideation, especially among boys. Conduct problems also remained robustly associated to suicidal thoughts (aOR 1.8, CI 1.3 to 2.6) after adjustment. The association with overweight was strengthened (aOR 1.9, CI 1.4 to 2.7), with a robust relationship demonstrated also even among boys (aOR 2.0, CI 1.1 to 3.4). In contrast; obesity was strongly associated with suicidal thoughts only among girls (aOR 3.1, CI 1.2 to 7.7). Further, smoking was associated with suicidal thoughts, specifically among girls (aOR 1.9, CI 1.2 to 3.1).

The effect of early alcohol intoxications on crude OR for suicidal thoughts weakened in models controlling for other variables; controlling for smoking in particular attenuated the strength of the associations. Such effects were also seen when the association with alcohol was investigated across 3 levels of increasing exposure (table 3). Attention problems, insomnia and early alcohol intoxications did not show statistically significant associations with suicidal thoughts in the fully integrated model.

The protective effect of physical activity was evident among boys (aOR 0.6 CI 0.4 to 0.9 ) but not significantly among girls (aOR 0.7 CI 0.5 to 1.1). Further stratified analyses showed that the protective association was evident in the group not reporting early alcohol intoxication(s) (OR 0.6, CI 0.4 to 0.8 ), compared to the group with early intoxication (OR 1.0, CI 0.6 to 1.6 ).

\section{DISCUSSION}

Anxiety and depressive symptoms, together with pain and muscular tension, were associated with nearly doubled increased risk for the development of suicidal thoughts during adolescence; and more so in boys than girls. Attention problems also had a similar unadjusted effect that, we suspect, might be mediated through other health problems such as depression, visualised by reduced OR after adjustment in our analysis.

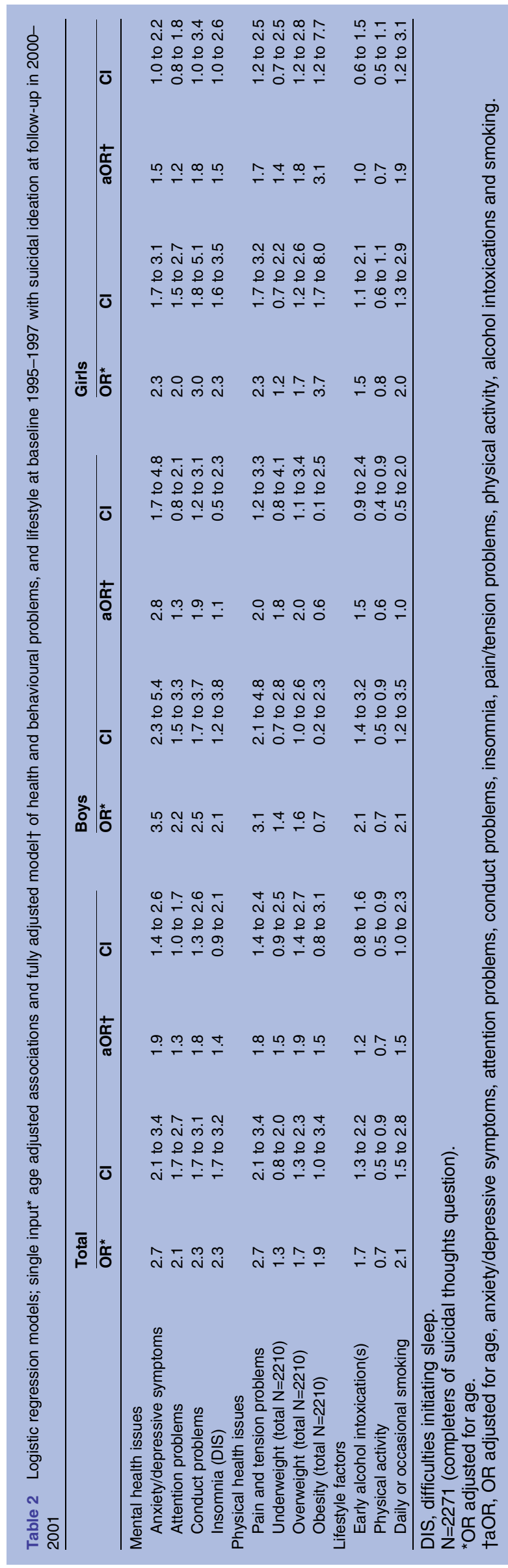




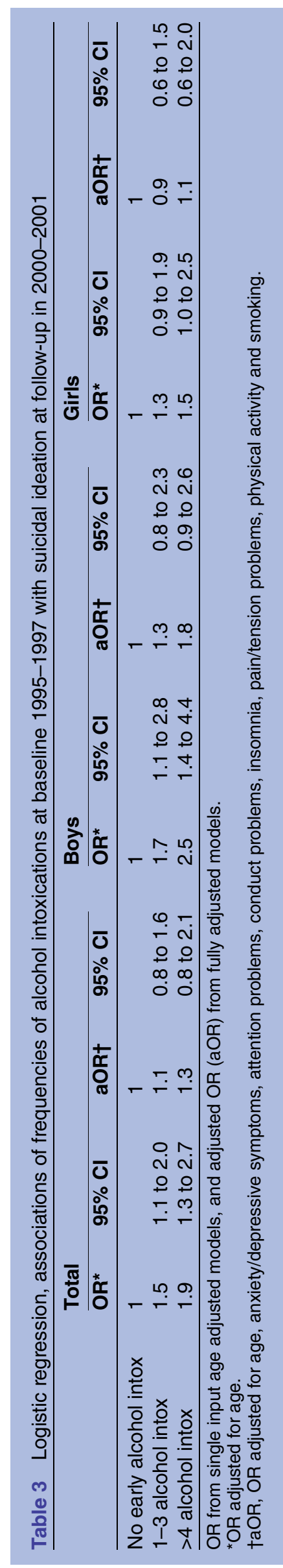

In accordance with previous suicide research, ${ }^{44}{ }^{45}$ we found that conduct problems robustly increased the odds for suicidal thoughts in both genders. Conduct problems as well as conduct disorder emerge early in child development, and include some degree of impulsivity, frustration, poor academic achievement, social marginalisation and, often, low self-esteem, ${ }^{46}$ all previously linked to suicidal behaviours and suicide. ${ }^{47}$ Using diagnostic categories, comorbidity in conduct disorder is common, especially with attention and hyperactivity disorders. ${ }^{48}{ }^{49}$ Features that are specific (eg, social reaction on rule breaking behaviour) and features that commonly occur within attention and conduct problems (such as impulsivity), can be the basis for development of suicidality. The link might also be mediated through development of depressive symptoms around puberty. However, our broad category of conduct problems seems robustly associated with suicidal thoughts even after controlling for depression and other possible confounders.

The observation that boys seemed more vulnerable to anxiety and depressive symptoms, is in accordance with a previous study on adolescents with major depressive disorder. ${ }^{26}$ The gender differences in findings may be related to the fact that depressive states are less frequent among boys, or might be reported by boys with more serious problems, thus representing a more extreme sample. The dissimilarity may also be due to different underlying causes and the stigma of anxiety and depression may be more socially excluding among boys than girls. ${ }^{26}$ Muscular pain and tension were formerly ${ }^{20}$ thought to be mediated through mental health problems. Our findings were, however, robust to adjustment, including anxiety and depression, and merit further study.

In relation to weight/BMI, the literature indicates that the epidemiology and mechanisms of suicide ideation and suicide attempts differ from those leading to a completed suicide. ${ }^{13}$ Consistently, population-based studies of adults have demonstrated a negative association of BMI with risk of completed suicide. In contrast, and in line with our findings among girls, several studies have demonstrated an increased risk of suicidal ideation and suicide attempts in the obese. ${ }^{14}{ }^{50}$ Overweight might be less socially accepted in girls compared to boys and body image perspective more dominant. Owing to an earlier onset of puberty, girls were physically more mature than boys at baseline, and this difference might have influenced our results.

Alcohol use disorders are frequently recorded in studies of completed suicide, ${ }^{51}$ yet our findings show a marginal association of early alcohol intoxications and development of suicidal thoughts. Alcohol intoxications at baseline might not represent an ideal measure to link early alcohol use to later suicidal ideation. Binge drinking is a common social activity among Norwegian teenagers, and might involve protective and risk inducing factors. For instance, adolescents not drinking at all 
might be more lonely and isolated. Alcohol intoxication might initialise an impulsive attempt rather than generating suicidal thoughts. In addition, early alcohol involvement can act as a modifier on other risk factors. Additional analysis in our study confirmed that early alcohol intoxication nearly doubled the effect anxiety/ depressive symptoms had on suicidal ideation.

Smoking increased odds for suicidal thoughts in our study, but was heavily correlated with early alcohol intoxication. Of the 244 adolescents reporting smoking at baseline, 199 (82\%) also reported early alcohol intoxications. Alcohol use and smoking can be perceived as experimental and deviant behaviour among persons under 16 . They tend to identify with the same group of adolescents, sharing many risk factors, including conduct problems.

Among Norwegian adolescents, physical activity seemed moderately protective against suicidal ideation, but the effect was most evident among boys and among students without alcohol experience in secondary school. Moderating effects of gender and alcohol use on health behaviour are also reported in some newer studies. $^{52-54}$

\section{Strengths and limitations}

The Young-HUNT Study is a total population study with a high response rate and few drop-outs even at follow-up. The study thus was representative for the population in Nord-Trøndelag and Norway, at that time, but more importantly, it represents a baseline for general studies of later health effects for many years to come. The study was designed for prospective investigations, with approximately 4 years' follow-up time. Even if 4 years seems little in prospective studies, these years represent a great leap in adolescent development. The questionnaire included a broad collection of health and lifestyle background variables, some prevalidated, and some tested in former research from the Young-HUNT Study. ${ }^{55}$ None of the variables used have diagnostic precision, but represent broader problem groups in a majority of otherwise healthy adolescents.

However, some limitations have to be pointed out. The Regional Committee for Medial and Research Ethics was concerned that even asking a question about suicidal thoughts might initiate suicidal thinking and did not allow the question in secondary school at the time. Exclusion of adolescents with suicidal thoughts at baseline was thus not possible, so the study is based on lifetime suicidal thoughts reported at follow-up. Other studies have confirmed that suicidal thoughts develop between the age of 13 and $18,{ }^{56}$ supporting our assumption of suicidal thoughts mostly emerging during follow-up time. Questions about self-harm were also excluded.

In the third year of high school, some students were attending vocational training and were not at school when the study was conducted. They were invited by post, but the response rates were low $(34 \%)$. This represents a possible social bias, but former studies have compared the baseline responses of the missing at follow-up, without finding any disturbing skewness. ${ }^{31}$

The fully adjusted models require answers in all variables, and there is no way to be totally sure that the 1911 informants in the adjusted analysis are representative for the whole cohort, but the similarity in results in crude ORs and adjusted ORs are reassuring.

According to existing literature and our factor analysis, it is not possible to separate anxiety from depression in SCL-5. The measure used in this study, therefore, represents the symptom load of mixed anxiety and depression. Evidence from the adult population supports the premise that mixed anxiety and depression, rather than any single condition, is strongly associated with suicide. $^{5758}$

\section{Conclusion and implications}

Suicidal thoughts are frequent among high school students in Norway. In this study, anxiety/depression, conduct problems, overweight, together with pain and tension at the age of 13-15 years, were strongly associated with developing suicidal thoughts during late adolescence. The importance of externalising behaviour seems under-communicated in the actual debate about risk factors and prevention of suicidal behaviours. ${ }^{59}$

The role of early alcohol intoxication remained inconclusive, while physical activity might protect from suicidal thoughts among boys.

To study the pathway from suicidal thoughts to completed suicide, large-scale population-based studies with specified baseline measures on suicidal behaviours should be linked with hospital and mortality registries.

\section{Author affiliations}

${ }^{1}$ Department of Child and Adolescent Psychiatry, Levanger Hospital, NordTrøndelag Health Trust, Levanger, Norway

${ }^{2}$ Department of Public Health and General Practice, Faculty of Medicine (ISM), HUNT Research Centre, Norwegian University of Science and Technology (NTNU), Levanger, Norway

${ }^{3}$ Faculty of Health Sciences, Nord-Trøndelag University College (HiNT), Levanger, Norway

${ }^{4}$ Department of Neuroscience, Faculty of Medicine, Norwegian University of Science and Technology, Trondheim, Norway

${ }^{5}$ School of Social and Community Medicine, University of Bristol, Bristol, UK

${ }^{6}$ Department of Psychiatry, Levanger Hospital, Nord-Trøndelag Health Trust, Levanger, Norway

Acknowledgements The Nord-Trøndelag Health Study (The HUNT Study) is a collaboration between HUNT Research Centre, ISM, (Faculty of Medicine, Norwegian University of Science and Technology NTNU), Nord-Trøndelag County Council, Central Norway Health Authority and the Norwegian Institute of Public Health.

Contributors AS formed the idea and method, analysed, wrote the draft, coordinated and finished the manuscript. OB contributed in developing the idea, background and writing of the manuscript. DGcontributed in developing the idea with the corresponding author, supervision in choice of methods and the background literature in addition to writing of the article. SB developed the age-stratified and sex-stratified weight variable, has extensively written and also commented in the development of the article. TLH, PI of the Young-HUNT study, is the method supervisor and also took part in forming the text. NB contributed to the development of ideas, writing and the general progress in the work with the article. 
Funding This article was funded as part of a $\mathrm{PhD}$ project by a grant from the Liaison Committee between the Central Norwegian Health Authority and the Norwegian University of Science and Technology. In addition, North-Trøndelag County has contributed to the project.

Competing interests None.

Patient consent Obtained.

Ethics approval REK-Middle-Norway.

Provenance and peer review Not commissioned; externally peer reviewed.

Data sharing statement Technical appendix, statistical details and data set are accessible from the corresponding author. Extra data can be made available by emailing Young-HUNT PI, Professor Turid Lingaas Holmen, turid. lingaas.holmen@ntnu.no

Open Access This is an Open Access article distributed in accordance with the Creative Commons Attribution Non Commercial (CC BY-NC 4.0) license, which permits others to distribute, remix, adapt, build upon this work noncommercially, and license their derivative works on different terms, provided the original work is properly cited and the use is non-commercial. See: http:// creativecommons.org/licenses/by-nc/4.0/

\section{REFERENCES}

1. Fergusson DM, Lynskey MT. Suicide attempts and suicidal ideation in a birth cohort of 16-year-old New Zealanders. J Am Acad Child Adolesc Psychiatry 1995;34:1308-17.

2. Nock MK, Borges G, Bromet EJ, et al. Cross-national prevalence and risk factors for suicidal ideation, plans and attempts. $\mathrm{Br} J$ Psychiatry 2008;192:98-105.

3. Ten HM, de Graaf R, van Dorsselaer S, et al. Incidence and course of suicidal ideation and suicide attempts in the general population. Can J Psychiatry 2009;54:824-33.

4. Boden JM, Fergusson DM, Horwood LJ. Anxiety disorders and suicidal behaviours in adolescence and young adulthood: findings from a longitudinal study. Psychol Med 2007;37:431-40.

5. Bradvik L, Mattisson $\mathrm{C}$, Bogren $\mathrm{M}$, et al. Long-term suicide risk of depression in the Lundby cohort 1947-1997-severity and gender. Acta Psychiatr Scand 2008;117:185-91.

6. Brent DA. Risk factors for adolescent suicide and suicidal behavior: mental and substance abuse disorders, family environmental factors, and life stress. Suicide Life Threat Behav 1995;25(Suppl):52-63.

7. Enns MW, Cox BJ, Afifi TO, et al. Childhood adversities and risk for suicidal ideation and attempts: a longitudinal population-based study. Psychol Med 2006;36:1769-78.

8. Sund AM, Larsson B, Wichstrom L. Psychosocial correlates of depressive symptoms among 12-14-year-old Norwegian adolescents. J Child Psychol Psychiatry 2003;44:588-97.

9. Wichstrom L. Predictors of adolescent suicide attempts: a nationally representative longitudinal study of Norwegian adolescents. J Am Acad Child Adolesc Psychiatry 2000;39:603-10.

10. Chronis-Tuscano A, Molina BS, Pelham WE, et al. Very early predictors of adolescent depression and suicide attempts in children with attention-deficit/hyperactivity disorder. Arch Gen Psychiatry 2010;67:1044-51.

11. Evans E, Hawton K, Rodham K. Factors associated with suicidal phenomena in adolescents: a systematic review of population-based studies. Clin Psychol Rev 2004;24:957-79.

12. Gunnell D, Harbord R, Singleton N, et al. Factors influencing the development and amelioration of suicidal thoughts in the genera population. Cohort study. Br J Psychiatry 2004;185:385-93.

13. Bjerkeset $\mathrm{O}$, Romundstad $\mathrm{P}$, Evans $\mathrm{J}$, et al. Association of adult body mass index and height with anxiety, depression, and suicide in the general population: the HUNT study. Am J Epidemiol 2008;167:193-202.

14. Carpenter KM, Hasin DS, Allison DB, et al. Relationships between obesity and DSM-IV major depressive disorder, suicide ideation, and suicide attempts: results from a general population study. $A m \mathrm{~J}$ Public Health 2000;90:251-7.

15. Crow S, Eisenberg ME, Story $M$, et al. Are body dissatisfaction, eating disturbance, and body mass index predictors of suicidal behavior in adolescents? A longitudinal study. J Consult Clin Psychol 2008;76:887-92.

16. Wilcox HC, Conner KR, Caine ED. Association of alcohol and drug use disorders and completed suicide: an empirical review of cohort studies. Drug Alcohol Depend 2004;76(Suppl):S11-19.
17. Borges G, Walters EE, Kessler RC. Associations of substance use abuse, and dependence with subsequent suicidal behavior. Am J Epidemiol 2000;151:781-9.

18. Chatterii P, Dave D, Kaestner R, et al. Alcohol abuse and suicide attempts among youth. Econ Hum Biol 2004;2:159-80.

19. Roane BM, Taylor DJ. Adolescent insomnia as a risk factor for early adult depression and substance abuse. Sleep 2008;31:1351-6.

20. Braden JB, Sullivan MD. Suicidal thoughts and behavior among adults with self-reported pain conditions in the national comorbidity survey replication. J Pain 2008;9:1106-15.

21. Woolley SB, Fredman L, Goethe JW, et al. Headache complaints and the risk of suicidal thoughts or behaviors. J Nerv Ment Dis 2008;196:822-8.

22. Bronisch T, Hofler M, Lieb R. Smoking predicts suicidality: findings from a prospective community study. J Affect Disord 2008;108:135-45

23. Sagatun A, Sogaard AJ, Bjertness E, et al. The association between weekly hours of physical activity and mental health: a three-year follow-up study of 15-16-year-old students in the city of Oslo, Norway. BMC Public Health 2007;7:155.

24. Sund AM, Larsson B, Wichstrom L. Role of physical and sedentary activities in the development of depressive symptoms in early adolescence. Soc Psychiatry Psychiatr Epidemiol 2011;46:431-41.

25. Groholt B, Ekeberg O, Wichstrom L, et al. Sex differences in adolescent suicides in Norway, 1990-1992. Suicide Life Threat Behav 1999;29:295-308

26. Lewinsohn PM, Rohde P, Seeley JR, et al. Gender differences in suicide attempts from adolescence to young adulthood. J Am Acad Child Adolesc Psychiatry 2001;40:427-34

27. Cantor C, Neulinger K. The epidemiology of suicide and attempted suicide among young Australians. Aust N Z J Psychiatry 2000;34:370-87.

28. Heuveline P, Slap GB. Adolescent and young adult mortality by cause: age, gender, and country, 1955 to 1994. J Adolesc Health 2002;30:29-34.

29. Boeninger DK, Masyn KE, Feldman BJ, et al. Sex differences in developmental trends of suicide ideation, plans, and attempts among European American adolescents. Suicide Life Threat Behav 2010:40:451-64.

30. Mather AA, Cox BJ, Enns MW, et al. Associations of obesity with psychiatric disorders and suicidal behaviors in a nationally representative sample. J Psychosom Res 2009;66:277-85.

31. Holmen TL, Bratberg G, Krokstad S, et al. Cohort profile of the Young-HUNT Study, Norway: a population-based study of adolescents. Int J Epidemiol 2014;43:536-44.

32. Strandheim A, Holmen TL, Coombes L, et al. Alcohol intoxication and mental health among adolescents-a population review of 8983 young people, 13-19 years in North-Trondelag, Norway: the Young-HUNT Study. Child Adolesc Psychiatry Ment Health 2009;3:18.

33. Strandheim A, Holmen TL, Coombes L, et al. Alcohol use and physical health in adolescence: a general population survey of 8,983 young people in North-Trondelag, Norway (the Young-HUNT study). Subst Use Misuse 2010;45:253-65.

34. Pedersen G, Karterud S. Is SCL-90R helpful for the clinician in assessing DSM-IV symptom disorders? Acta Psychiatr Scand 2004;110:215-24.

35. Tambs K, Moum T. How well can a few questionnaire items indicate anxiety and depression? Acta Psychiatr Scand 1993;87:364-7.

36. Strand $\mathrm{BH}$, Dalgard OS, Tambs $\mathrm{K}$, et al. Measuring the menta health status of the Norwegian population: a comparison of the instruments SCL-25, SCL-10, SCL-5 and MHI-5 (SF-36). Nord $J$ Psychiatry 2003;57:113-18.

37. Storksen I, Roysamb E, Moum T, et al. Adolescents with a childhood experience of parental divorce: a longitudinal study of mental health and adjustment. J Adolesc 2005;28:725-39.

38. Storksen I, Roysamb E, Holmen TL, et al. Adolescent adjustment and well-being: effects of parental divorce and distress. Scand $J$ Psychol 2006;47:75-84.

39. Neckelmann D, Mykletun A, Dahl AA. Chronic insomnia as a risk factor for developing anxiety and depression. Sleep 2007;30:873-80.

40. Booth ML, Okely AD, Chey $\mathrm{T}$, et al. The reliability and validity of the physical activity questions in the WHO health behaviour in schoolchildren (HBSC) survey: a population study. Br J Sports Med 2001;35:263-7.

41. Bjornelv S, Lydersen S, Mykletun A, et al. Changes in BMl-distribution from 1966-69 to 1995-97 in adolescents. The Young-HUNT study, Norway. BMC Public Health 2007;7:279.

42. Cole TJ, Flegal KM, Nicholls D, et al. Body mass index cut offs to define thinness in children and adolescents: international survey. BMJ 2007;335:194. 
43. Strandheim A, Bratberg GH, Holmen TL, et al. The influence of behavioural and health problems on alcohol and drug use in late adolescence-a follow up study of 2399 young Norwegians. Child Adolesc Psychiatry Ment Health 2011;5:17.

44. Engqvist U, Rydelius PA. Death and suicide among former child and adolescent psychiatric patients. BMC Psychiatry 2006;6:51.

45. Harris EC, Barraclough B. Suicide as an outcome for mental disorders. A meta-analysis. Br J Psychiatry 1997;170:205-28.

46. Glass K, Flory K, Martin A, et al. ADHD and comorbid conduct problems among adolescents: associations with self-esteem and substance use. Atten Defic Hyperact Disord 2011;3:29-39.

47. Kirkcaldy BD, Siefen GR, Urkin J, et al. Risk factors for suicidal behavior in adolescents. Minerva Pediatr 2006;58:443-50.

48. Huh Y, Choi I, Song M, et al. A comparison of comorbidity and psychological outcomes in children and adolescents with attention-deficit/ hyperactivity disorder. Psychiatry Investig 2011;8:95-101.

49. Rutter M. Research review: Child psychiatric diagnosis and classification: concepts, findings, challenges and potential. J Child Psychol Psychiatry 2011;52:647-60.

50. Brunner J, Bronisch T, Pfister $\mathrm{H}$, et al. High cholesterol, triglycerides, and body-mass index in suicide attempters. Arch Suicide Res 2006;10:1-9.

51. Galaif ER, Sussman S, Newcomb MD, et al. Suicidality, depression, and alcohol use among adolescents: a review of empirical findings. Int J Adolesc Med Health 2007;19:27-35.
52. Barry AE, Piazza-Gardner AK. Drunkorexia: understanding the co-occurrence of alcohol consumption and eating/exercise weight management behaviors. J Am Coll Health 2012;60:236-43.

53. Buscemi J, Martens MP, Murphy JG, et al. Moderators of the relationship between physical activity and alcohol consumption in college students. J Am Coll Health 2011;59:503-9.

54. Kwan MY, Cairney J, Faulkner GE, et al. Physical activity and other health-risk behaviors during the transition into early adulthood: a longitudinal cohort study. Am J Prev Med 2012;42:14-20.

55. Bratberg GH, Nilsen TI, Holmen TL, et al. Sexual maturation in early adolescence and alcohol drinking and cigarette smoking in late adolescence: a prospective study of 2,129 Norwegian girls and boys. Eur J Pediatr 2005;164:621-5.

56. Glowinski AL, Bucholz KK, Nelson EC, et al. Suicide attempts in an adolescent female twin sample. J Am Acad Child Adolesc Psychiatry 2001;40:1300-7.

57. Mykletun A, Bierkeset O, Dewey M, et al. Anxiety, depression, and cause-specific mortality: the HUNT study. Psychosom Med 2007;69:323-31.

58. Bjerkeset $\mathrm{O}$, Mykletun A, Dahl AA, et al. Mortality in relation to self-reported mixed anxiety and depression symptoms - the HUNT study. Nord J Psychiatry 2007;61:6-11.

59. Nordentoft M. Prevention of suicide and attempted suicide in Denmark. Epidemiological studies of suicide and intervention studies in selected risk groups. Dan Med Bull 2007;54:306-69. 